\section{Comment on: Impact of a multidisciplinary intensive education program on type 2 diabetes mellitus patients' glycemic control and cardiovascular risk factors}

\section{To the Editor}

Type 2 diabetes mellitus (T2DM) is a chronic disease which carries high morbidities and an increased in cardiovascular risk which is responsible of at least one third of the all mortality related to diabetes mellitus. ${ }^{1}$ A common pathway in managing T2DM is the multidisciplinary approach for the control of cardiovascular risk factors. It has been shown in Steno-2 trail that multiple risk factors management resulted in reduction of both micro- and macro-vascular complications of T2DM which is reflected on the long term follow up to a decline in mortality. ${ }^{2,3}$

The study by Al-Arif and $\mathrm{Al}-\mathrm{Omar}^{4}$ was interesting and will enrich the Saudi literature. The observed results which showed improvement in glycemic control, diastolic blood pressure, total cholesterol, and lowdensity lipoprotein after application of multidisciplinary approach. This study stresses on the collaborative work to manage T2DM especially in patients with uncontrolled blood sugar. The management of diabetes mellitus requires involvement of different teams including physicians, nutritionists, diabetes educators (nurse), and psychologists. This study with no doubt, demonstrates the importance of such approach. These results are supported by similar studies in the literature which showed reproducibility of the outcomes. However, there are certain concerns which need to be addressed. This is a small, and retrospective study which lack the control group.

The setting of the study is in a primary health care, thus, the results might not reflect a wide variety of difficult cases which are managed in specialized diabetes centers. In this study, the only inclusion criteria to define high risk patients was poor glycemic control to send them for multidisciplinary intensive education program. However, the high risk group might contain a wider variety of individuals including; young onset T2DM, patients with comorbidities such as chronic renal failure or heart failure, and more. Furthermore, the major improvement of HbAlc happens in the first 3 months, then it was steady in the subsequent study period. Although $\mathrm{HbAlc}$ was not in the optimal target there was no explanation what further interventions were offered to these patients. Additionally, it would be better if the updated mean HbAlc was calculated since it gives a better predictive power in relation to complications as compared with mean HbA1c. ${ }^{5}$ Finally, the data would be stronger if it was correlated with diabetes outcomes.

In conclusion, the results of this trial is concordant with similar studies which emphasize the importance of the collaborative approach in the managing patients with T2DM. A larger randomized controlled trail may be needed in a specialized center to challenge these results.

\section{Abdulghani H. Al Saeed Department of Endocrine and Diabetes Prince Sultan Military Medical City Riyadh, Kingdom of Saudi Arabia \\ ORCID ID: https://orcid.org/0000-0003-2949-174X}

\section{Reply from the Author}

We would like to thank you dearly for your interest and praise of our work. We agree with you regarding your concern of the study population, steady A1C level, and its correlation with diabetes outcome. However, the scientific and medical research is a continuing process. Therefore, being a retrospective study design we faced this limitation due to the availability of the data. We hope that other future study will address this concern.

Mohamed N. Al-Arifi
Hussain A. Al-Omar
Clinical Pharmacy Department
King Saud University
Riyadh, Kingdom of Saudi Arabia

\section{References}

1. Leon BM, Maddox TM. Diabetes and cardiovascular disease: epidemiology, biological mechanisms, treatment recommendations and future research. World J Diabetes 2015; 6: 1246-1258.

2. Gæde P, Lund-Anderson H, Parving HH, Pedersen O. Effect of a multifactorial intervention on mortality in type 2 diabetes. $N$ Engl J Med 2008; 358: 580-59.

3. Gaede P, Oellgaard J, Carstensen B, Rossing P, Lund-Anderson $\mathrm{H}$, Parving HH. Years of life gained by multifactorial intervention in patients with type 2 diabetes mellitus and microalbuminuria: 21 years follow-up on the Steno-2 randomised trial. Diabetologia 2016; 59: 2298-2307.

4. Al-Arifi $\mathrm{M} \mathrm{N}, \mathrm{Al}-\mathrm{Omar} \mathrm{H} \mathrm{A}$. Impact of a multidisciplinary intensive education program on type 2 diabetes mellitus patients' glycemic control and cardiovascular risk factors. Saudi Med J 2018; 39: 705-710.

5. Lind M, Oden A, Fahlen M, Eliasson B. The true value of hbalc as a predictor of diabetic complications: simulations of HbA1c variables. PLoS One 2009; 4 : e4412. 